e-ISSN 2344-8172 Vol. 10, No. 19 julio diciembre 2021 | DOI: https://doi.org/10.17230/map.v10.i19.01

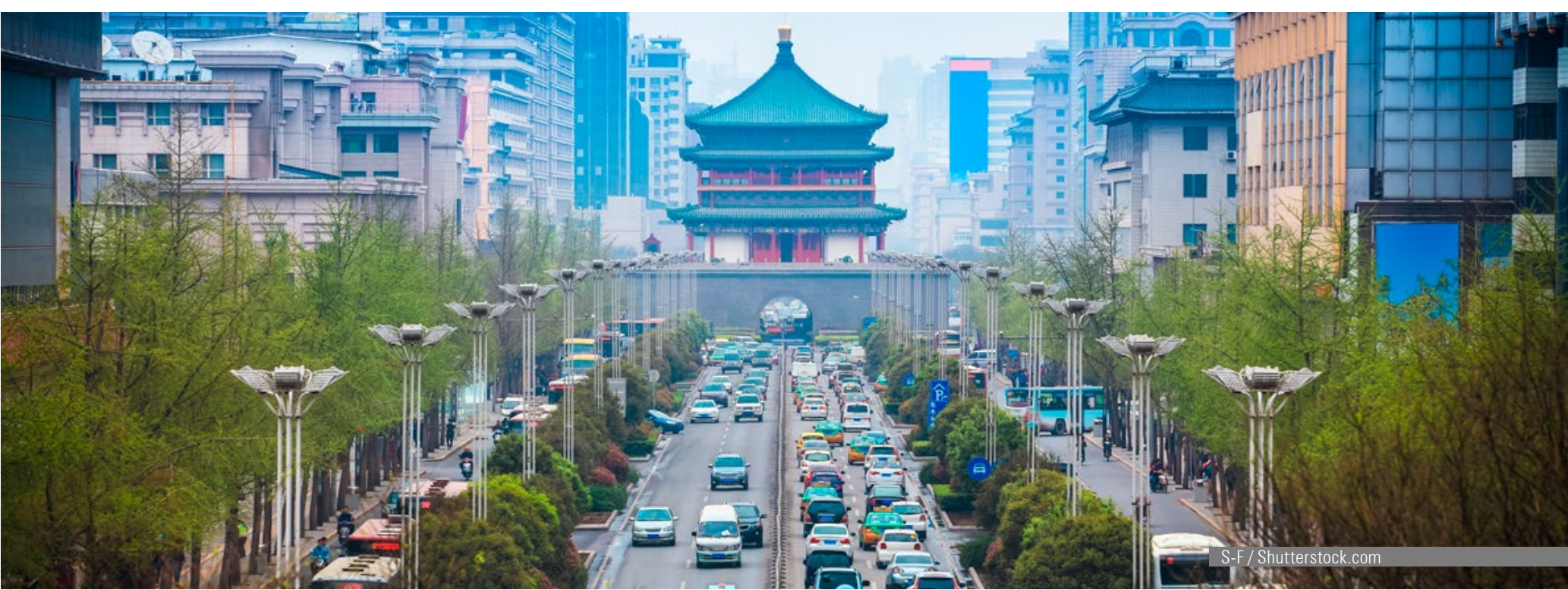

\title{
Modos de distribución de vehículos chinos en los países de la Alianza del Pacífico
}

\section{Distribution methods of Chinese vehicles in the Pacific Alliance countries}

\section{Otto Regalado-Pezúa}

Doctor en Ciencias de gestión por la Université de Nice-Sophia Antipolis (Francia) Universidad ESAN (Perú) oregalado@esan.edu.pe https://orcid.org/0000-0001-6196-1479

\section{Miguel Angel Montoya Bayardo}

Doctor en Economía Aplicada. Universidad Autónoma de Barcelona (España) Tecnológico de Monterrey. Campus Guadalajara (México) mmontoya@tec.mx https://orcid.org/0000-0002-5545-6334

\section{Gabriel Arnaldo Zapata Pezúa} Ingeniero Industrial por la Universidad Peruana de Ciencias Aplicadas (UPC) Investigador independiente gabriel.zp@gmail.com

Recibido: 26 de septiembre Aprobado: 9 de noviembre Publicado: 17 de diciembre

\section{Resumen}

Cuando la industria automotriz china decidió expandirse al mercado occidental tuvo que evaluar la mejor alternativa para comercializar sus marcas en los mercados segmentados y elegidos, entre ellos los países que conforman la Alianza del Pacífico. El presente artículo, basado principalmente en fuentes secundarias, desarrolla, por un lado, desde un enfoque conceptual, los modos de distribución implementados por las marcas de automóviles en general; y, por otro lado, desde un enfoque aplicado, las estrategias de distribución seguidas por cuatro marcas chinas elegidas: Changan, Great Wall, JAC y BAIC en los mercados de Chile, Colombia, México y Perú.

\section{Palabras clave}

Distribución, industria automotriz, marcas chinas, Alianza del Pacífico

\section{Abstract}

When the Chinese automotive industry decided to expand into the western market, it had to evaluate the best alternative for marketing its brands in the segmented and selected markets, including the countries that form the Pacific Alliance. This article, based mainly on secondary sources, develops, on the one hand, through a conceptual approach, the distribution methods implemented by automotive brands in general, and on the other hand, through an applied approach, the distribution strategies of the four Chinese brands 
that were selected —Changan, Great Wall, JAC, and BAIC — in the markets of Chile, Colombia, Mexico, and Peru.

\section{Keywords}

Distribution, automotive industry, Chinese brands, Pacific Alliance

\section{Introducción}

El sector automotor, en los países donde se asienta, constituye un motor de desarrollo por los beneficios que representa para sus economías en aspectos como el consumo, la generación de empleo y el ingreso de divisas, así como en la mejora de la calidad de transporte de sus habitantes. Si bien esta industria está bien desarrollada en Estados Unidos, Europa y el continente asiático, se espera que también se desarrolle en los países que constituyen la Alianza del Pacífico (AP) y en general en toda América Latina y el Caribe (ALC), región que ya representa el cuarto mercado más grande del mundo.

En América Latina se distinguen tres grupos de países. El primero de ellos, compuesto únicamente por Brasil que, por el tamaño de su población y mercado, consume prácticamente la totalidad de los vehículos que ensambla. El segundo grupo de países tiene un doble comportamiento: ensambla y exporta una parte de su producción, pero también importa vehículos para abastecer el mercado local. Aquí se ubican países de gran tamaño como Colombia, México y Venezuela. El tercer grupo de países está conformado por países que no tienen industria automotriz local y solo importan vehículos para cubrir su mercado, entre ellos, Chile y Perú (BBVA Research, 2010).

Este panorama atrajo la atención de la industria automotriz china, que decidió establecer alianzas estratégicas con la finalidad de instalar plantas de ensamblaje de vehículos en sitios estratégicos con la finalidad de introducir estos al mercado local y posteriormente expandirse a otros mercados de la región.

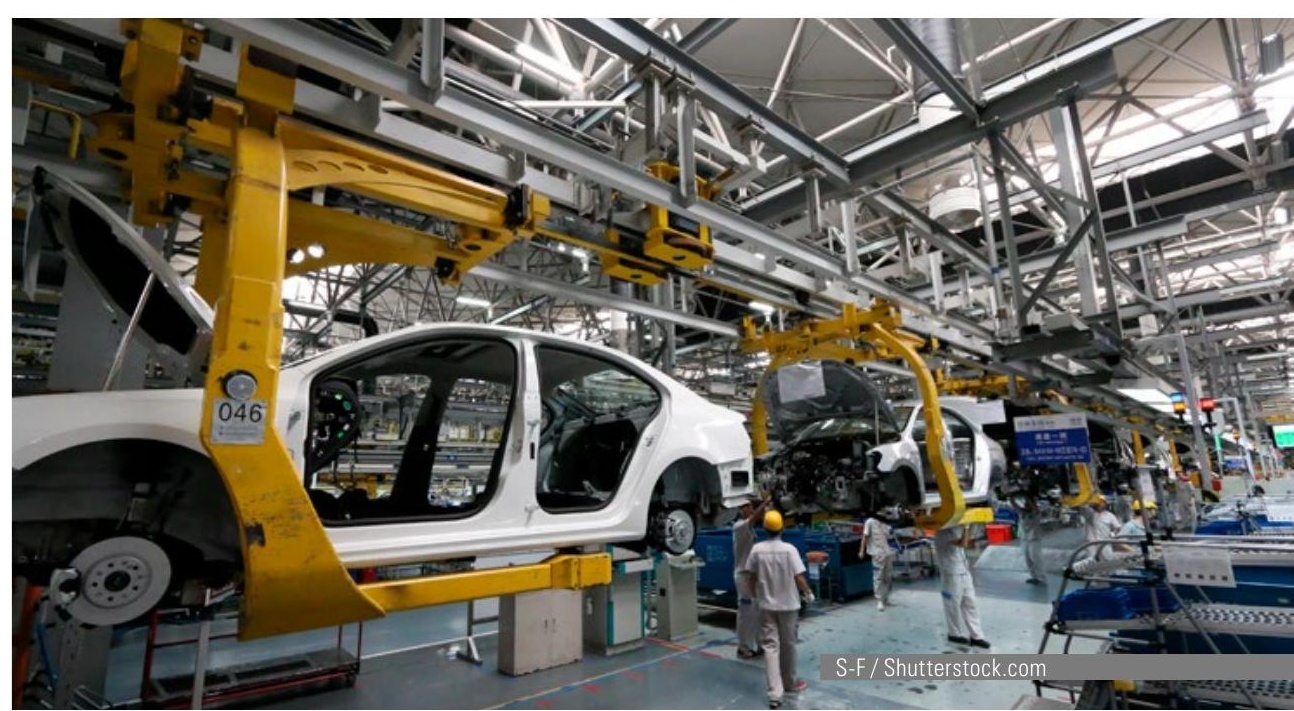

En el presente artículo, en una primera parte, y desde un enfoque conceptual, se desarrollan los modos de distribución de la industria automotriz china en los mercados donde están presentes. En una segunda parte, se presenta un análisis del sector automotor en cada uno de los países que conforman la AP. Y en la tercera parte, desde un enfoque aplicado, se pre- 
senta un análisis de cuatro marcas chinas que se comercializan en Chile, Colombia, México y Perú.

\section{Estrategias de distribución en el sector automotor}

En la industria automotriz, los distribuidores son un agente determinante en el proceso de comercialización; están a cargo del marketing, la promoción y de plantear las estrategias de venta de vehículos (Kamiya \& Ramirez, 2004). Durante mucho tiempo la distribución de vehículos trabajaba bajo un formato de distribución indirecta, es decir, mediante franquicias otorgadas por la casa matriz a diferentes concesionarios presentes en los mercados previamente definidos. Sin embargo, debido a la alta penetración de internet en los últimos años, se han presentado cambios en los canales de venta y en las estrategias de comunicación de las marcas para acercarse a los consumidores con diferentes perfiles (Fitzen, 2007). De esta manera, el acceso a internet de la población ha impulsado a las empresas a desarrollar nuevos canales y permitido a los usuarios más información de los automóviles de su interés. Actualmente, la distribución de vehículos es realizada utilizando varios canales de distribución y venta, como se observa en la Figura 1.

Figura 1. Distribución de vehículos

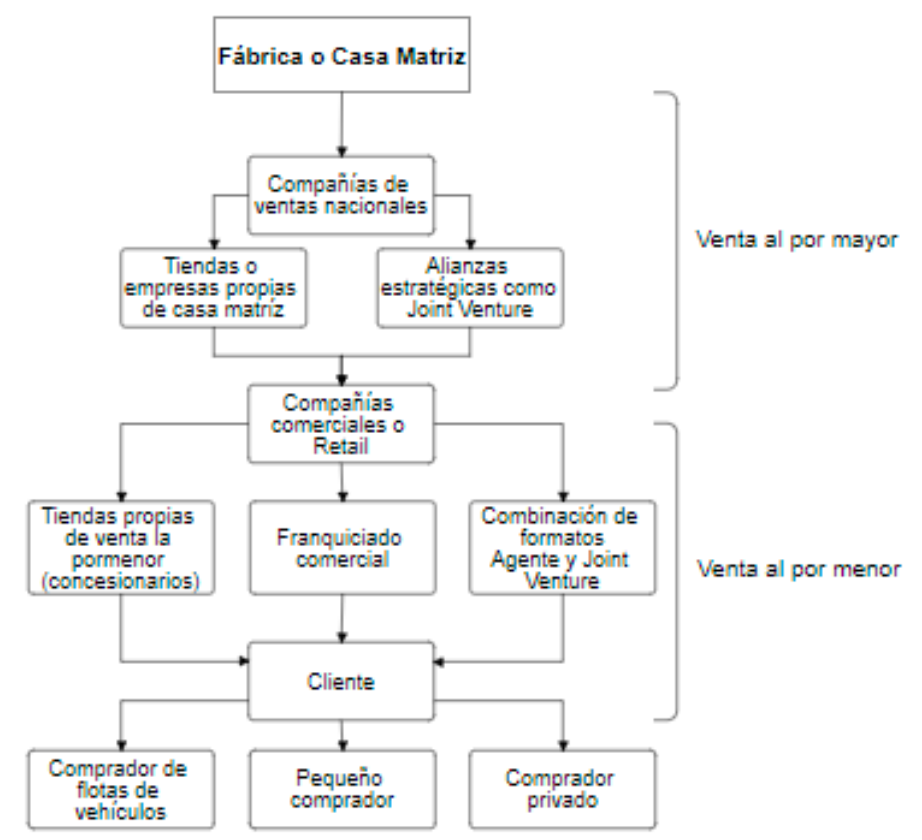

Fuente: Basado en Fitzen (2007).

En el Sistema de marketing vertical (SVM) basado en contratos, la distribución de vehículos se coordina desde su fabricación, por parte del fabricante, hasta su comercialización por parte de los distribuidores mayoristas y concesionarios automotrices. En el SMV se mantiene el control sobre los intermediarios que intervienen a lo largo de todo este proceso con el fin de cumplir con los objetivos de marketing trazados. Sin embargo, en la actualidad este modelo tradicional está perdiendo competitividad frente a la implementación del sistema omnicanal.

Por su parte, la omnicanalidad, como su nombre lo indica, se basa en la integración y gestión de diferentes canales de distribución (e-commerce, redes sociales, vía telefónica, tiendas físicas, etc.) que facilitan la comunicación 
con el cliente para la comercialización de vehículos. Asimismo, la omnicanalidad permite obtener una mayor cobertura de mercado a un menor costo de venta, siempre y cuando se disponga de la infraestructura tecnológica y física para soportar dicha operación. A raíz de la pandemia muchas empresas automotrices han optado por realizar ventas directas a través de internet, ofreciendo información del vehículo, como características técnicas, colores y versiones disponibles, facilidades de pago, entre otros con la finalidad de ofrecer una compra segura al momento de efectuar una compra.

Para Homburg et al. (2012), las compañías automotrices emplean varios canales a través de la combinación de distribuidores mayoristas, concesionarios y comercio electrónico para llegar de forma directa al cliente, tal como se observa en la Figura 2.

\section{Figura 2. Distribución multicanal}

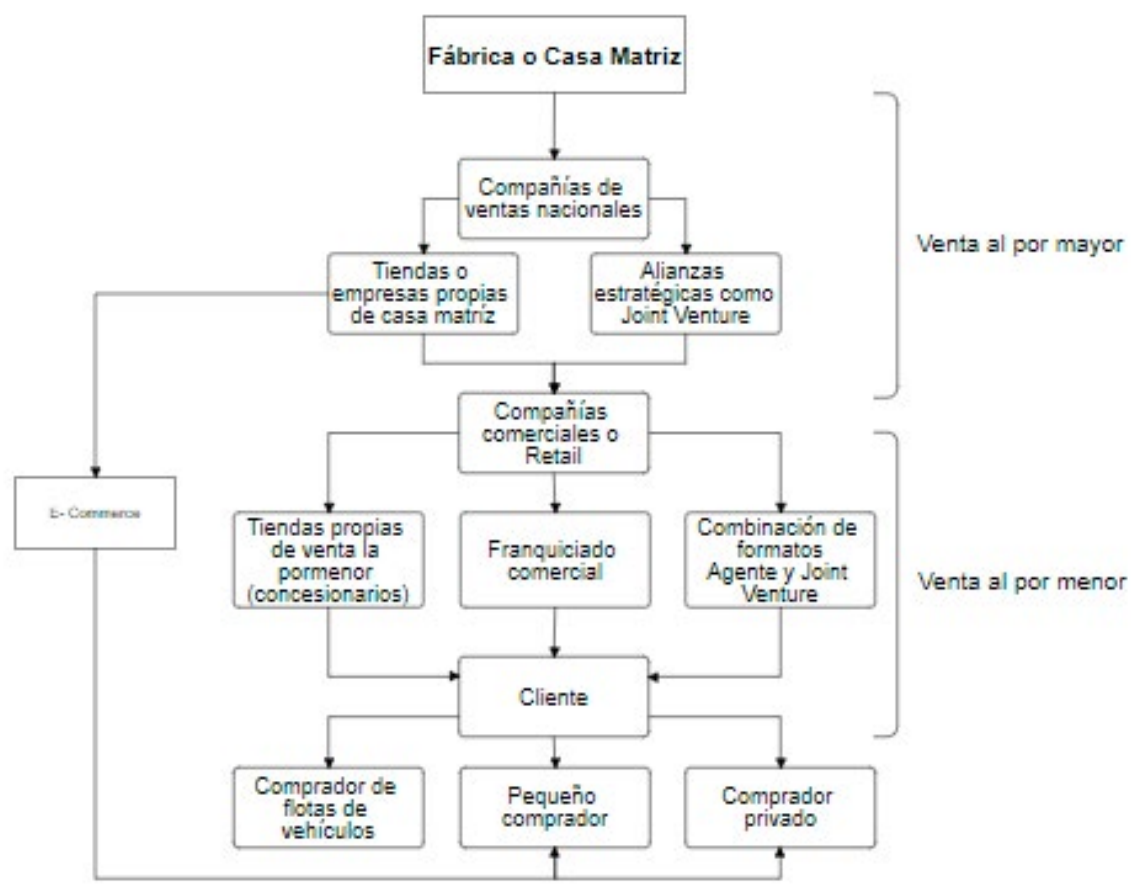

Fuente: Homburg et al. (2012)

Actualmente, es posible encontrar este sistema de distribución en diferentes países de la región, en el cual se suscriben contratos entre el fabricante y diferentes concesionarios para que estos últimos puedan obtener la distribución exclusiva de determinadas marcas, con la condición de que estas no puedan comercializar vehículos de otras marcas (González E. , 2015).

Para González (2015), la distribución exclusiva promueve inversiones considerables y gastos en servicios posventa que contribuyen al mejoramiento del proceso de distribución y expansión de la oferta. La distribución exclusiva, como su nombre lo indica, permite a los concesionarios tener la comercialización de determinadas marcas.

En el caso de las marcas chinas, se suscribe un contrato a través del cual estos fabricantes conceden la distribución de sus vehículos a concesionarios locales y/o regionales, como es el caso por ejemplo de Derco, una concesionaria multimarca que opera en Bolivia, Chile, Colombia y Perú, que comercializa la línea de vehículos de la marca JAC. Como concesionario multimarca, Derco también comercializa bajo contrato la distribución de otras marcas de 
vehículos livianos como Changan, Great Wall y Haval, para ello realiza los pedidos y órdenes de compra con seis meses de anticipación.

A pesar de que la gran mayoría de marcas chinas tienen fábricas en el continente asiático desde donde se realizan los procesos de manufactura, ensamble y despacho a los diferentes países del mundo, solo algunas de estas marcas han instalado plantas de ensamblaje en países como Brasil, Colombia, Ecuador, México, Paraguay y Uruguay, donde distribuyen algunos modelos a los diferentes mercados de la región (Marklines, s.f.).

\section{Análisis del sector automotor por país miembro de la Alianza del Pacífico}

A continuación, en el presente acápite se desarrolla un breve análisis de la industria automotriz en cada uno de los países miembros de la AP:

\section{Chile}

Chile se encuentra ubicado en el extremo sudoeste de América del Sur, cuenta con una superficie de 756.096 km²; su población está estimada en 19,1 millones de habitantes y una densidad poblacional de 25 habitantes por $\mathrm{km}^{2}$. Según la Cámara Nacional de Comercio Automotriz de Chile, en el año 2019 circularon 5,59 millones de vehículos, 746.320 unidades más que en 2016 (CAVEM, 2020). Solo las ventas de vehículos nuevos livianos y medianos fueron de 372.882 en 2019 a comparación de las 258.835 unidades en 2020 (ANAC, 2021), esto representa una caída del 30,6 \% con respecto al 2019.

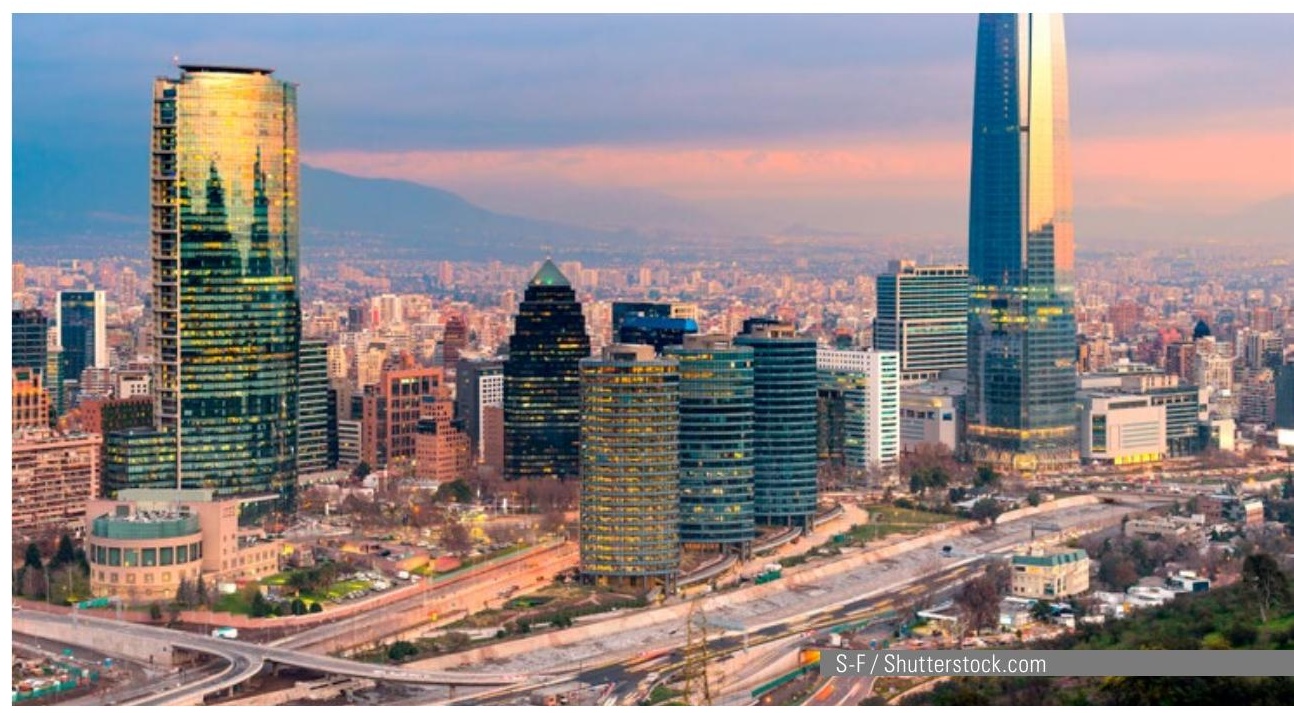

A pesar de la contracción en las ventas de vehículos por efectos de la pandemia, la preferencia de los consumidores se concentró en vehículos SUV con un 37,6 \% del mercado, 34,7 \% en vehículos de pasajeros, 17,4 \% en camionetas y solo el 10,2 \% en vehículos comerciales (ANAC, 2020).

En Chile, actualmente, existen más de 61 marcas de vehículos livianos y medianos, de estas marcas, por lo menos 20 son de origen chino (ANAC, 2020). Algunas de ellas han estado presentes en el mercado chileno desde 2007; en ese tiempo el porcentaje de participación de estas marcas en el mercado no superaba 2 \%. En 2008 la participación de autos chinos subió a 5,7 \% y para 2010 el porcentaje de participación en el mercado chileno ya era mayor a $10 \%$. A principios de 2020 las marcas chinas abarcaron el $16 \%$ de 
participación en el mercado automotriz, ubicándolas en tercer lugar entre las favoritas, por detrás de las marcas coreanas y japonesas (La Tercera, 2020). Actualmente, según la Asociación Nacional Automotriz de Chile (ANAC), el porcentaje de participación de las marcas chinas en el segmento del mercado de vehículos livianos y medianos es del $19 \%$, ubicándose en el segundo lugar después de las marcas japonesas cuyo mercado abarca el 30 \% del mercado automotriz chileno, siendo las marcas más vendidas MG, Chery, Changan, JAC y Great Wall (ANAC, 2020).

Anteriormente, los autos chinos se caracterizaban por ofrecer vehículos cero kilómetros a bajo precio. Sin embargo, actualmente se destacan por ofrecer un conjunto de atributos adicionales como: equipamiento completo, precio razonable y gran diseño. Esto también se ve reflejado en el servicio posventa, factor clave en el proceso de decisión al momento de evaluar la compra de un auto (América Economía, 2017).

Por otro lado, Chile está apostando por la movilidad limpia y para ello ha establecido una estrategia que incluye el uso de vehículos eléctricos como monopatines, autos, taxis y buses eléctricos con la finalidad de reducir la contaminación en Santiago de Chile, una de las ciudades más contaminadas del país sureño. El objetivo del gobierno es renovar su parque automotor para que en 2050 el $100 \%$ de vehículos empleados para el transporte público sean eléctricos, así como el 40 \% de vehículos de transporte privado (Reuters, 2018).

\section{Colombia}

Colombia se encuentra ubicada en la región noroccidental de Sudamérica. Limita con Venezuela y Brasil por el este y con Ecuador y Perú por el sur. Este país tiene una superficie de 1'141.748 km²y una población que sobrepasa los 50 millones de habitantes, su densidad poblacional es de 44 habitantes por km² (Datosmacro.com, 2021), lo que lo posiciona como el tercer país más poblado en Latinoamérica después de Brasil y México.

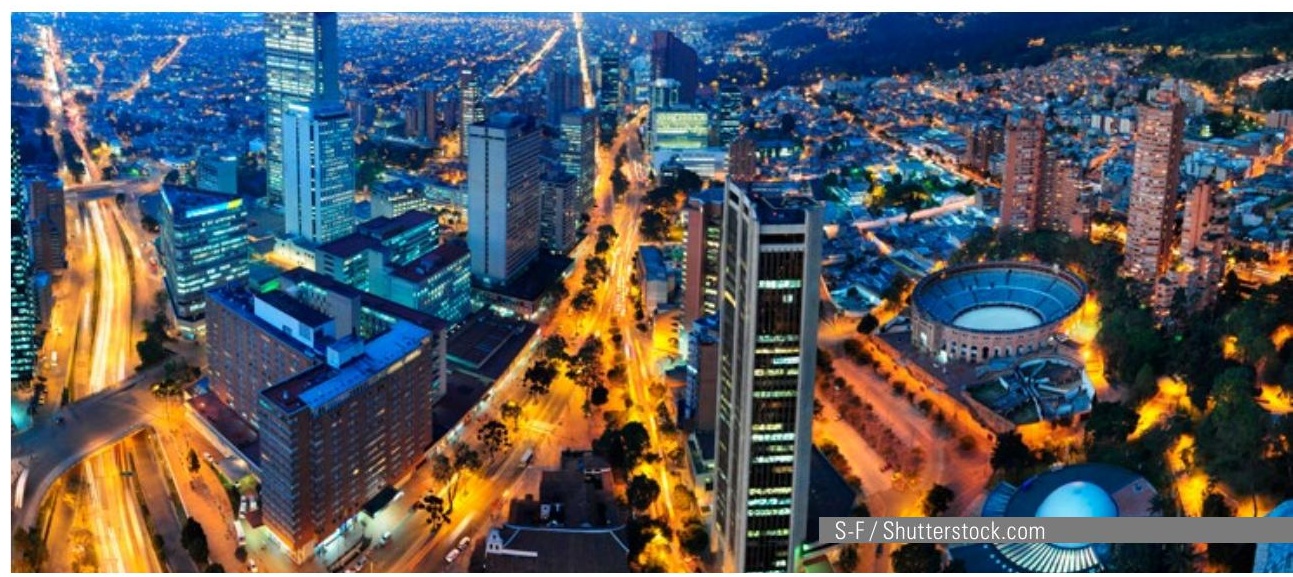

En Colombia circulan más de 15 millones de vehículos motorizados, de los cuales el 8,9 millones son motos (es decir el 59 \%) y 6,2 millones son vehículos de transporte particular o público, entre otros (El Tiempo, 2020). A diferencia de otros países, Colombia tiene un mercado potencial amplio dada la baja penetración de vehículos. Para 2018 había 120 vehículos por cada 1.000 habitantes, ubicándolo por debajo de Argentina y Chile, con 316 vehículos y 248 vehículos por cada 1.000 habitantes (BBVA Research, 2018).

La industria automotriz colombiana está compuesta por empresas ensambladoras y fabricantes de partes y accesorios. Según Procolombia (2020), Colombia es el cuarto fabricante de vehículos y el segundo de motoci- 
cletas en América Latina. Esta industria contribuye con el 6,2 \% del PBI y emplea a casi $2,5 \%$ de la población en actividades de ensamblaje de vehículos destinados al mercado local y regional, solo en 2019 se vendieron 263.320 vehículos y 604.960 motocicletas. Los principales mercados a los cuales se exportan estos vehículos particulares y de carga son México, Ecuador, Bolivia. Chile, Argentina y Perú.

Según Procolombia (2018), se esperaba que un crecimiento en las ventas de $7,7 \%$ durante el periodo 2019 y 2023, crecimiento que estaría impulsado por mejoras en las condiciones económicas, el crecimiento de la clase media, acceso al mercado financiero, desarrollo de proyectos de infraestructura vial, mejoras de seguridad del país y a la renovación del parque automotor. Sin embargo, por efectos de la pandemia del coronavirus, las ventas de autos nuevos en Colombia se contrajeron en un 37,7 \% durante el primer semestre de 2020 (ACARA, 2020). Para finales del año 2020, esta caída en las ventas fue de 28,.5\% con respecto al 2019 (Andemos, 2021).

Con fundamento en las cifras y estadísticas obtenidas de la Asociación Nacional de Movilidad Sostenible (Andemos), se ha podido identificar 40 marcas de vehículos chinos que compiten en diferentes segmentos del mercado colombiano. En el segmento de automóviles se puede encontrar marcas como Oransh, MG, BYD, Brilliance, Jiayuan, JAC, las cuales aún tienen una baja participación en comparación con otras más consolidadas como Chevrolet, Renault, Nissan o Kia. En el segmento de vehículos comerciales para transporte de carga se pueden encontrar marcas como Foton, JAC, JMC, Changan y Sinotruck. En el segmento de vehículos comerciales para transporte de pasajeros se encuentran marcas como BYD, Yutong, Sunwin y Golden Dragon. En el segmento de vehículos utilitarios están presentes Lifan, JAC, Landwind, JMC, Great Wall, Foton, FAW, DSFK, Chery, Changan, BYD, BAIC y MG. Entre las marcas chinas, lideraron las ventas en 2020 Foton con 2.781 unidades, JAC con 2.262 unidades, JMC con 1.108 unidades, Changan con 862 unidades y DSFK con 668 unidades (Andemos, 2020). De este grupo, Foton y JMC han realizado estudios de factibilidad para instalar plantas de ensamblaje en Colombia con la finalidad reducir los aranceles provenientes de la importación de vehículos, atender mejor las necesidades del mercado local y poder llegar a otros mercados en la región (El Tiempo, 2015) (Portafolio, 2017).

Colombia, al igual que otros países de la región, ha emprendido un programa de renovación de vehículos, con la finalidad de promover su industria automotriz y reducir los problemas de contaminación que tienen otras ciudades como México y China. Por esta razón, se está comenzando a impulsar el uso de vehículos híbridos y eléctricos sobre todo para el segmento de transporte masivo, el cual está conformado en su mayoría por buses y camiones que superan los 20 años de antigüedad (RUNT, 2018).

\section{México}

Este país tiene una extensión de 1'959.375 km², se encuentra ubicado en América del Norte, comparte frontera con Estados Unidos por el norte y con Belice y Guatemala por el sur. Con una población estimada que bordea los 125 millones de habitantes (EY, 2018), México es el segundo país más poblado de Latinoamérica después de Brasil. Según información obtenida del Instituto Nacional de Estadística y Geografía —INEGI—, en el año 2019 circularon más de 50,5 millones de vehículos, de los cuales el 90 \% son automóviles, camiones de carga y de pasajeros, mientras que el $10 \%$ son otros vehículos como motocicletas y de servicio oficial (INEGI, 2019). 


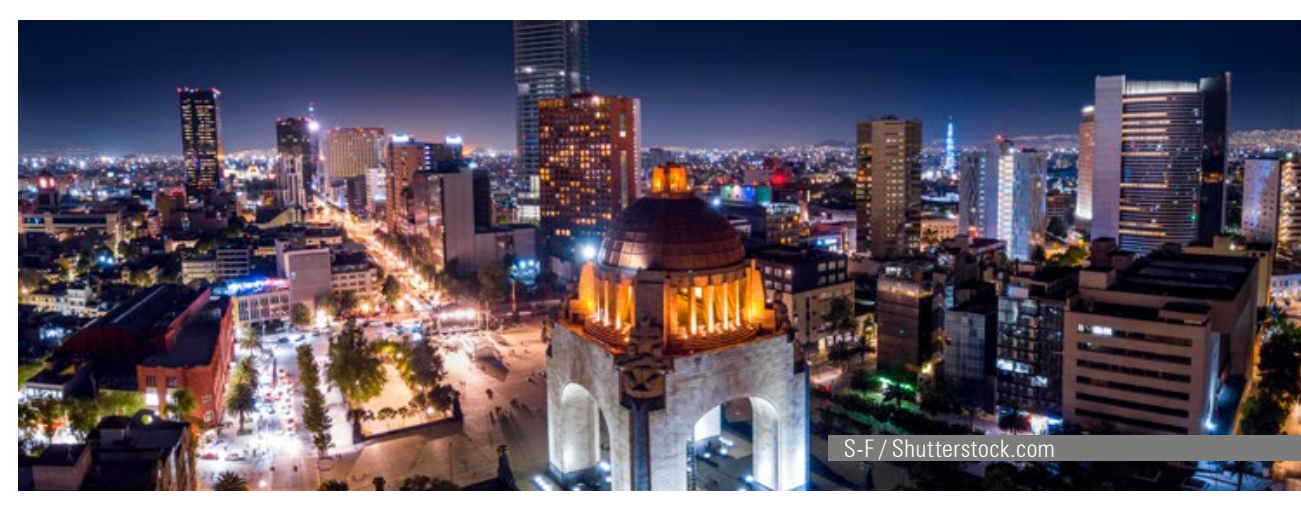

En 2019, la industria automotriz mexicana contribuyó con la economía del país en 148 millones de dólares, lo que representa el 3 \% del PIB. Asimismo, la producción automotriz está destinada principalmente al mercado de exportación (88 \% de una producción total de 3,7 millones de autos producidos ese año), ubicándola como el sexto productor de automóviles en el mundo y el cuarto que más exporta, solamente detrás de Alemania, Japón y Estados Unidos (BBVA Research, 2020).

Esto se debe a que, en los últimos 25 años, la industria automotriz mexicana ha sido una de las más dinámicas y competitivas del mundo gracias a las preferencias arancelarias del Tratado de Libre Comercio de América del Norte (NAFTA por sus siglas en inglés) que mantiene con Estados Unidos y Canadá. Este tipo de acuerdo, sumado a la ubicación geográfica del país, mano de obra barata y bajos costos de operación, han atraído la atención de empresas extranjeras como Volkswagen, Nissan, Honda, BMW, Mazda, Toyota, Kia, Hyundai, Audi, entre otras, que han invertido en instalar plantas de fabricación y ensamblaje.

A pesar de que Estados Unidos es el principal destino de las exportaciones mexicanas, en los últimos años México ha diversificado las exportaciones de vehículos a otros países de Latinoamérica como Brasil, Colombia, Argentina, Chile y Perú.

En los últimos nueve años ha aumentado la participación de los fabricantes asiáticos como Nissan, Toyota y Honda en el mercado mexicano, que pasó de $35 \%$ a 50,8 \%. Este cambio en las preferencias de los mexicanos hacía los vehículos asiáticos obedece a la buena calidad, tango del producto (ahorro de combustible) como del el servicio posventa (costos de mantenimiento accesible). En el mercado mexicano también existen otras marcas asiáticas, como las coreanas Kia y Hyundai, que compiten con estrategias más agresivas en cuanto a producto, garantías, instalaciones y servicio post venta, lo que ha obligado a subir el estándar de referencia del mercado (Sánchez, 2017). Bajo este escenario, empresas como BAIC y JAC han iniciado proyectos en México, con lo que se suman a la lista de armadoras de vehículos de pasajeros con presencia en el país mientas que otras empresas como MG, Changan y BYD, tienen presencia a través de representantes o concesionarios autorizados.

\section{Perú}

Con una extensión de 1'285.220 km² y una población de 32 millones de habitantes, Perú es el cuarto país más poblado de América del Sur después de Brasil, Colombia y Argentina. Actualmente circulan más de 3 millones de vehículos, de los cuales el 59 \% son automóviles y station wagon, 26 \% son camionetas, el $3 \%$ son buses, el $8 \%$ son camiones y el 4 \% estaría conformado por remolcadores, remolques y semi remolques. Lima es el departamento 
que concentra el mayor número de autos (66 \%), seguido de La Libertad y Arequipa (Posada, 2018).

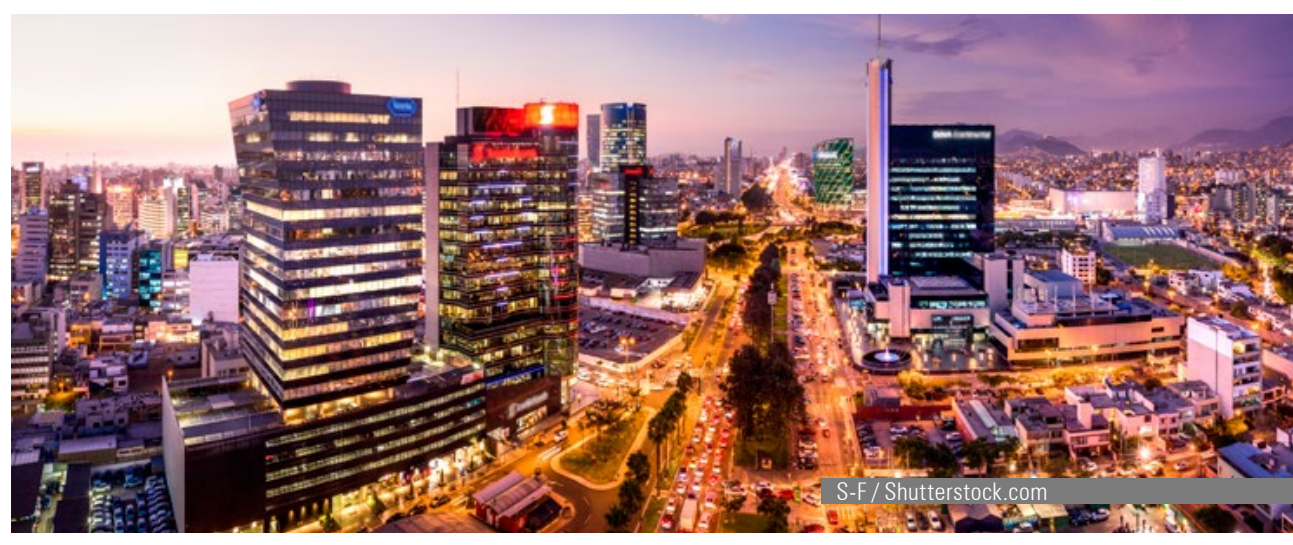

El parque automotor peruano es uno de los más antiguos de América Latina, actualmente bordea los 13 años de antigüedad, asimismo posee un índice de motorización de 10,7 habitantes por vehículo, un índice bastante bajo en comparación con otros países de la región como Argentina, México y Chile que tienen en promedio entre 3 y 3,33 habitantes por vehículo (AAP, 2019) (AAP, 2020). La necesidad de renovar el parque automotor peruano radica en que actividades económicas como la minería requieren de unidades vehiculares para llevar a cabo sus operaciones. Asimismo, se requiere reducir los niveles de contaminación del aire, congestión vehicular y transporte público (El Comercio, 2018)

En 2020 solo pudieron venderse 112.181 vehículos livianos (segmento conformado por automóviles, station wagons, camionetas, pick ups, furgonetas, SUV y todoterrenos), 12.909 vehículos pesados (camiones, tractocamiones, minibuses y omnibuses) y 285.661 vehículos menores (motos y trimotos), cifras menores a la de otros años, como producto de la pandemia, el aislamiento obligatorio y la paralización de gran número de actividades económicas que golpearon la economía.

En vehículos livianos, marcas como Toyota, Hyundai y Kia son las más comercializadas en ese segmento. Sin embargo, se encuentran marcas chinas como Changan, JAC, DFSK, Great Wall, Chery, Jinbei, Foton, MG, entre otros. El segmento de vehículos pesados es liderado por marcas como Mercedes Benz, Hino e Isuzu; sin embargo, también participan marcas chinas como Foton, JAC, Sinotruck, Dongfeng, Forland, Sachman, Joylong, King long, TKing y Yutong (AAP, 2021).

Según información estadística de la AAP (2021), en el segmento de vehículos ligeros las marcas chinas han logrado tener una participación del $15 \%$ en las ventas en 2020, un crecimiento de $2 \%$ con respecto al año 2019. Las marcas más vendidas en este segmento del mercado han sido Changan, con 4.164 unidades; JAC, con 3.116 unidades y DFSK, con 2.928 unidades. Por su parte, en el sector de vehículos pesados los productos chinos han obtenido una participación de $21 \%$ en ventas en 2020, un incremento del $3 \%$ con respecto a 2019. Las marcas más vendidas en este segmento del mercado han sido Foton, con 662 unidades; JAC, con 617 unidades y Dongfeng, con 369 unidades (AAP, 2021).

Las marcas chinas están posicionándose cada vez más en el mercado peruano. En ventas de autos chinos en la región, Perú ocupa el quinto lugar de Sudamérica, por debajo de Brasil, Argentina, Chile y Colombia. 


\section{Marcas chinas presentes en la Alianza del Pacífico}

En el presente acápite se desarrolla un breve análisis de una muestra de cuatro marcas chinas: Changan, Great Wall, JAC y BAIC presentes en los cuatro países de la AP estudiados previamente.

\section{Changan}

Changan es una empresa que desarrolla, diseña, produce y vende vehículos de pasajeros, vehículos comerciales y camiones ligeros (Bloomberg, 2021).

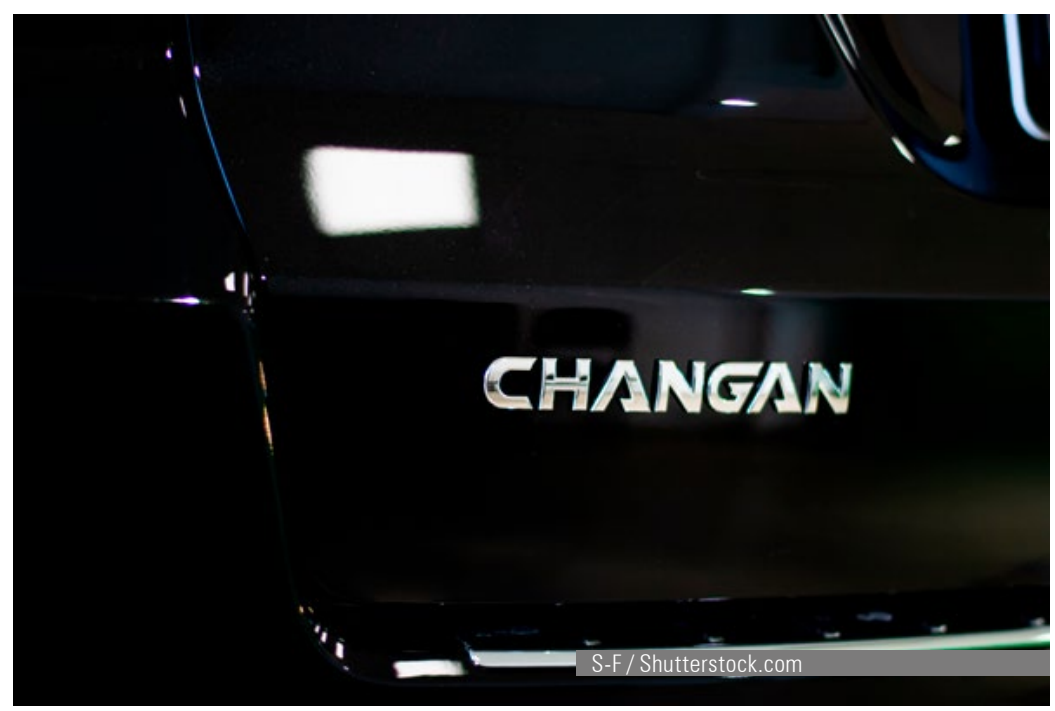

En 2008 ingresó al mercado chileno bajo la representación del concesionario Derco Chile. En ese año se comercializaron 2.520 vehículos livianos y medianos de la marca, obteniendo tan solo una participación del 1,1\% del mercado (ANAC, 2008). Mientras que, en 2020, se comercializaron 6.726 vehículos, obteniendo 2,6 \% de participación en el segmento total de vehículos livianos y medianos. Entre las unidades más vendidas están los SUV (5.198 unidades, con una participación del 5,3 \% con respecto a SUV de otras marcas) y vehículos comerciales (1.150 unidades, con una participación del 4,3 $\%$ con respecto a los vehículos comerciales de otras marcas) (ANAC, 2020).

La marca también está presente en Colombia desde 2004; en sus inicios estuvo bajo la representación de Grupo China Automotriz, un distribuidor con más de 40 años en el negocio y con concesionarios en todo el país (Revista Carga Pesada, 2014), y aunque los primeros vehículos en ser comercializados en este país fueron de carga, posteriormente se fueron introduciendo otros para diferentes segmentos del mercado como el SUV CS35, el auto compacto Benni y el crossover CX 20. Comautomotriz S.A representa la marca, una compañía que tiene más de 60 años en el sector automotor (Changan Colombia, 2021). Según la Asociación Colombiana de Vehículos Automotores, en 2018 Changan vendió 805 unidades, un 63 \% más que en 2017 (Andemos, 2018). Mientras que en 2019 solo alcanzó a vender 730 unidades, registrando una caída de 9,3\% con respecto 2018. En el segmento de vehículos ligeros y medianos ha mantenido una participación del 0,3\%. Mientras que, en el segmento de vehículos comerciales, donde la competencia es muy reducida, su participación ha sido del 5,6 \% en 2019 (Andemos, 2019).

En México, por su lado, Changan introdujo a finales de 2008 un lote de vehículos al mercado con la finalidad de que se realicen pruebas en el mercado mexicano. En 2009 anunció un joint venture con Autopark México y Magna 
Steyr, para instalar una planta ensambladora en el país, pero no llegó a concretarse (Gachúz, 2011). La planta de ensamblaje, que hubiera entrado en funcionamiento a finales de 2009 (Al Volante, 2008) (Jian, 2009), tendría una capacidad de producción de 50.000 vehículos al año y hubiera abastecido al mercado local, así como a otros mercados de la región, incluyendo Estados Unidos (Europa Press, 2009). La estrategia de Changan era entrar al mercado estadounidense sin tener que pagar aranceles gracias al NAFTA; sin embargo, la crisis financiera los obligó a cancelar dicho proyecto (Bermúdez, 2011). A pesar de todo ello, actualmente Changan se encuentra en la fase de búsqueda de una zona para instalarse e iniciar la producción de vehículos eléctricos en México (García, 2020).

En Perú, Changan está presente desde 2008 bajo la representación de Derco Perú, el cual comercializa una amplia gama de automóviles, SUV, vehículos multipropósitos y vehículos comerciales. En 2020 lograron comercializar 4,164 unidades, 1.037 unidades menos que en 2019, posicionándola en el puesto siete de las marcas automotrices que más se comercializan en el país y con una participación del 3,7 \% en el mercado (AAP, 2021).

\section{Great Wall}

Great Wall es una empresa privada cuyas acciones se cotizan en la bolsa de Hong Kong. Se dedica a la fabricación y venta de camionetas pick-up y vehículos deportivos - utilitarios (SUV), así como a trabajos de investigación y desarrollo $(I+D)$, fabricación de piezas y componentes automotrices (Bloomberg, 2021).

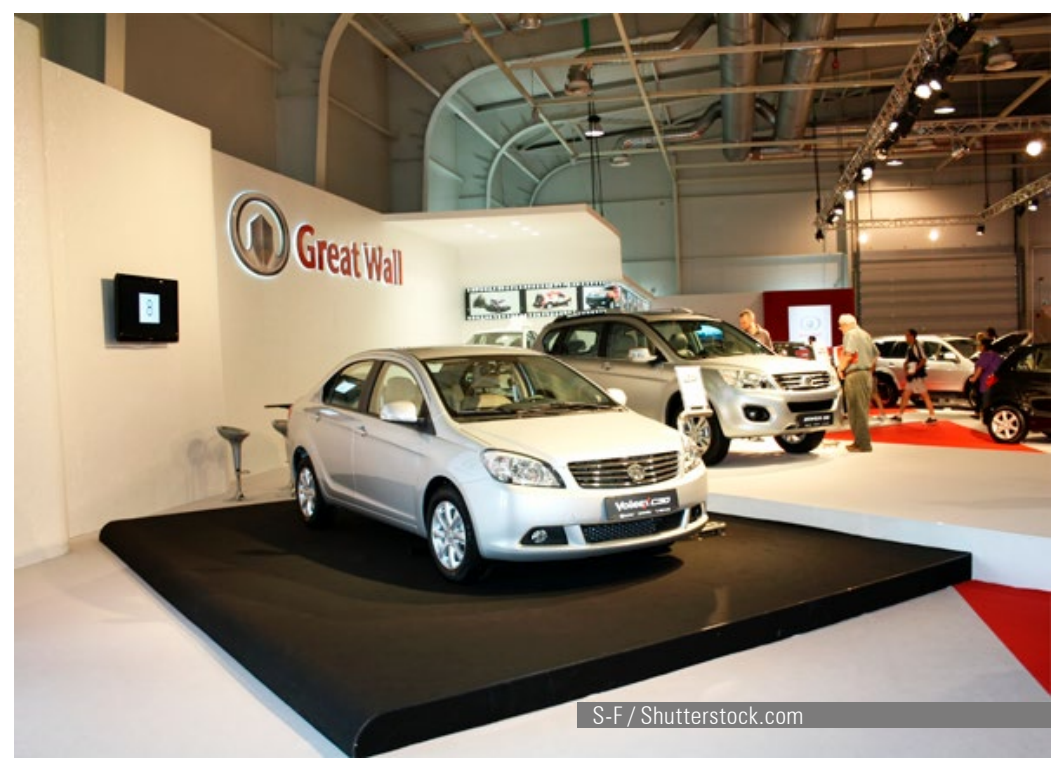

Great Wall está presente en el mercado chileno desde 2007, bajo la representación de Derco, concesionario de vehículos nuevos, usados y maquinaria. Entre los primeros vehículos que se comercializaron se encuentran las SUV Hover y Safe, así como la pick up Deer. En 2008 vendieron 3.544 unidades, con una participación del 1,5\% en dicho mercado. Posteriormente, fueron introduciendo nuevos modelos que se destacaron por su calidad, versatilidad, seguridad, confort y equipamiento, logrando que en 2012 Great Wall sea reconocida como la primera marca china en ser parte del Top 10 en ventas en Chile. Para 2019, Great Wall ya había vendido 60.000 unidades (Gutiérrez, 2019). En 2020, se comercializaron 4.902 vehículos de la marca, 
obteniendo una cuota de participación del 1,9\% en el mercado (ANAC, 2020).

En Colombia, Great Wall Motors estuvo representada por Derco desde 2010. A partir de 2018 la distribución de estos vehículos pasó a cargo de Ambacar, una empresa automotriz de amplia trayectoria en el mercado ecuatoriano y que opera en Perú, Costa Rica y Colombia (Ambacar, 2018). Ambacar está asociada a Ciauto, una planta ensambladora de vehículos Great Wall que opera en Ecuador desde 2013 (Alajo, 2014). En 2018, Ciauto firmó un contrato de inversión de 22 millones de dólares con la finalidad de consolidar el desarrollo de la industria automotriz ecuatoriana y exportar hacía Colombia (Enriquez, 2018) (Diario Expreso, 2018).

El primer vehículo de Great Wall comercializado en Colombia fue el Haval 3, un SUV muy parecido al Hover (Autosdeprimera.com, 2011). Otros modelos comercializados fueron el sedán Voleex C30, el hatchback Florid Cross y la pickup Wingle 5. También se comercializaron el Great Wall H6, H5 y M4, vehículos bien equipados y que ofrecen elegancia, confort y economía (EI Espectador, 2016).

En México, Great Wall anticipó a los gobiernos de Nuevo León y San Luis Potosí su interés en abrir una planta ensambladora en el país. Para esto, funcionarios de la empresa se reunieron con representantes de Ferrocarril Mexicano (Ferromex) y Kansas City Southern de México (KCSM) con la finalidad de evaluar la conectividad ferroviaria entre México y los Estados Unidos (Reuters, 2017). La construcción de una planta en México cubriría la demanda de vehículos en el mercado mexicano y norteamericano. Se estima que la inversión costará alrededor de 500 millones de dólares y tendrá una capacidad de producción de 250.000 automóviles al año (Reuters, 2017). Sin embargo, la guerra comercial con Estados Unidos y la renegociación del NAFTA han obligado a Great Wall a replantear la posibilidad de instalar su planta en Los Ángeles, donde tiene un centro de investigaciones que desarrolla versiones certificadas de sus vehículos Haval, con el fin de poder comercializarlos a partir de 2021.

En Perú, Great Wall es una de las marcas de vehículos de origen chino más vendida. Está presente en el país desde 2005, bajo la representación de Derco Perú. Entre los principales modelos destaca el automóvil de pasajeros Voleex C30 y C50; en el segmento de las SUV, cuenta con una amplia cartera de vehículos como el Great Wall H3, H5, H6 y el M4, mientras que en el segmento de pick-ups se pueden encontrar la Great Wall Wingle 5 (Derco Perú, s.f.). Durante 2016 Great Wall pudo sortear las dificultades y cerró el año con buenos resultados, el Voleex C30 ingresó al top 10 del ranking nacional de automóviles más vendidos en el mercado y ocupó el primer lugar entre los fabricantes de vehículos de origen chino. Mientras que la pick-up Wingle ocupó la octava posición de ventas en el país y el primer puesto de ventas entre los fabricantes chinos.

Según datos obtenidos de la AAP, en 2019 se vendieron 3.013 unidades, mientras que en 2020 las ventas fueron de 2.206 unidades, lo que equivale a una disminución de 26,8 \% en las ventas. Asimismo, en este último año Great Wall tuvo un porcentaje de participación de $2 \%$ del mercado, ubicándola en la posición 15 de las marcas automotrices que se comercializan en el país (AAP, 2021).

\section{JAC}

JAC es una empresa estatal dedicada a la fabricación y venta de una amplia gama de vehículos de carga, comerciales, de propósito especial, así como automóviles y autopartes (Bloomberg, 2021). 


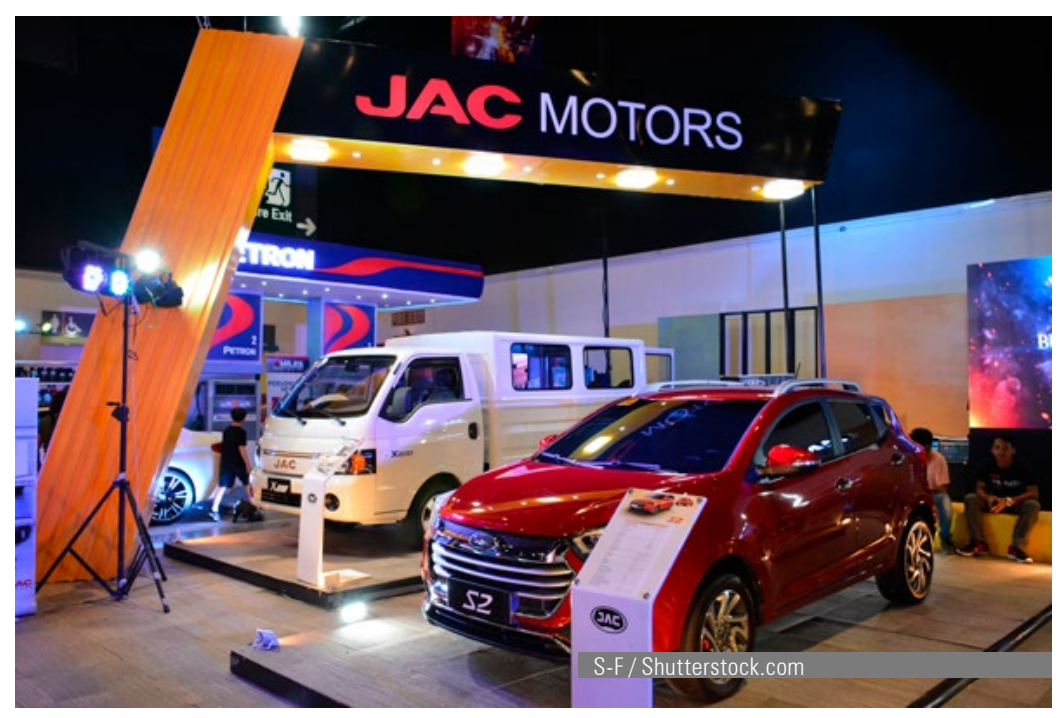

Llegó al mercado de Chile en 2008 bajo la representación de Derco. En ese primer año, solo se comercializaron 47 SUV y 41 camiones de la marca. Posteriormente y con el pasar de los años, se ha ido ampliando el portafolio de productos y mejorando la calidad de estos, como la camioneta JAC T6, la SUV S2 y el camión X200. Además, se incorporaron nuevas versiones a la línea de minibuses Sunray con motorización Cummins y nuevas versiones del JAC S2, JAC S3 con caja CVT, así como el nuevo y renovado S5. JAC fue la primera marca en Chile en ofrecer conexión a internet gratuita en sus modelos SUV S2, S3 y S5, el sedán J4 y la camioneta T6 por un período de 15 meses, lo que permite que el usuario pueda a través de las pantallas multifunción, que se encuentran instaladas en estos vehículos, hacer uso de aplicaciones como las de navegación y entretenimiento (Farias, 2017). Actualmente, JAC se encuentra dentro de las 20 marcas más vendidas en Chile. Solo en 2020 se vendieron 5.388 unidades, ocupando 2,1 \% de participación en el segmento de vehículos livianos y medianos (3.339 SUV, 1.104 camionetas, 607 vehículos comerciales y 338 vehículos de pasajeros) (ANAC, 2020).

En Colombia, JAC está presente desde 2016 bajo la representación de AutoCom. En ese país se han lanzado modelos como el crossover JAC S2 y la pickup mediana JAC T6. A partir de 2018 lanzó la JAC S7, un vehículo SUV para 7 ocupantes desarrollado en el Centro de Investigación y Desarrollo de JAC en Japón. Para consolidar su presencia en el mercado colombiano, JAC ha aprovechado el interés por los autos eléctricos para introducir el JAC E1, un vehículo eléctrico que comparte algunos rasgos con el city-car JAC Smile y el crossover JAC S2 Urban. El JAC E1 tiene un motor eléctrico es de 67 HP, el cual es alimentado por una batería de 29,2 kWh que ofrece una autonomía de 255 kilómetros.

Los vehículos JAC están disponibles en más de 19 ciudades; además, cuentan con el servicio técnico y de repuestos en 21 puntos del país. Según la Asociación Colombiana de Vehículos Automotores (Andemos), en 2018 JAC vendió 3.021 unidades, un 6 \% más que en 2017 y tuvo una participación del mercado de 1,2 \% (Andemos, 2018). En 2019 dicha participación bajó a 1 \%, ubicándola en el puesto 14 del ranking. Con respecto a vehículos de carga menor a las 10,5 toneladas, JAC ocupa el tercer puesto (Andemos, 2019).

En México, JAC Motors está presente desde 2007 con Giant Motors Latinoamérica (GML) para el ensamblaje de camiones ligeros y pesados. Sin embargo, a principios de 2017, Giant Motors decidió invertir 212 millones de 
dólares en la ampliación de planta. En esta inversión Inbursa, grupo financiero de propiedad de Carlos Slim y al cual pertenece Giant Motor, aportó el $50 \%$ del capital para la construcción, mientras que el resto se repartirá entre GML, JAC Motors y Chori, una empresa japonesa que dará financiamiento y proveeduría a nivel nacional y extranjera.

La planta ubicada en Hidalgo entró en operación en 2017 y tiene una capacidad de producción máxima de 40.000 vehículos al año, generándose así 1.000 empleos directos y 4.500 indirectos. Los compontes de los vehículos provienen de China mientras que otros son suministrados por proveedores locales. Los primeros modelos en ser fabricados fueron el SIE 2, SEI 3 y el $\mathrm{J} 4$, vehículos que son comercializados en el mercado mexicano y que posteriormente fueron exportados a países de Centro y Sudamérica (Vanguardia, 2017) (González L. , 2017).

En 2017, JAC logró comercializar 1.200 vehículos en el mercado mexicano (Cantera S. , 2018). Mientras que en 2020 se lograron vender 4.271 vehículos ligeros, de las cuales 3.782 unidades fueron producidas en México (INEGl, 2021). La comercialización de los vehículos JAC en México está a cargo de una red de concesionarios, entre los que se puede destacar al grupo Zapata y CAMSA, ubicados estratégicamente a lo largo del país.

En Perú, JAC es una marca dedicada a la fabricación de vehículos de pasajeros, comerciales, buses, eléctricos, motores, entre otros, es representada por Derco Perú. Esta concesionaria cuenta con 36 puntos de ventas a nivel nacional, 11 de ellas están ubicadas en Lima y 25 en provincias (Derco Perú, s.f.). Según la AAP, en 2020 se vendieron 3.116 unidades obteniendo una participación de 2,8 \% en el segmento de vehículos livianos y 550 vehículos pesados, con una participación del 4,3\% (AAP, 2021).

\section{BAIC}

BAIC es una empresa de propiedad estatal dedicada a la investigación, desarrollo, diseño y fabricación de vehículos y componentes (BAIC Perú, 2021) (Bloomberg, 2021).

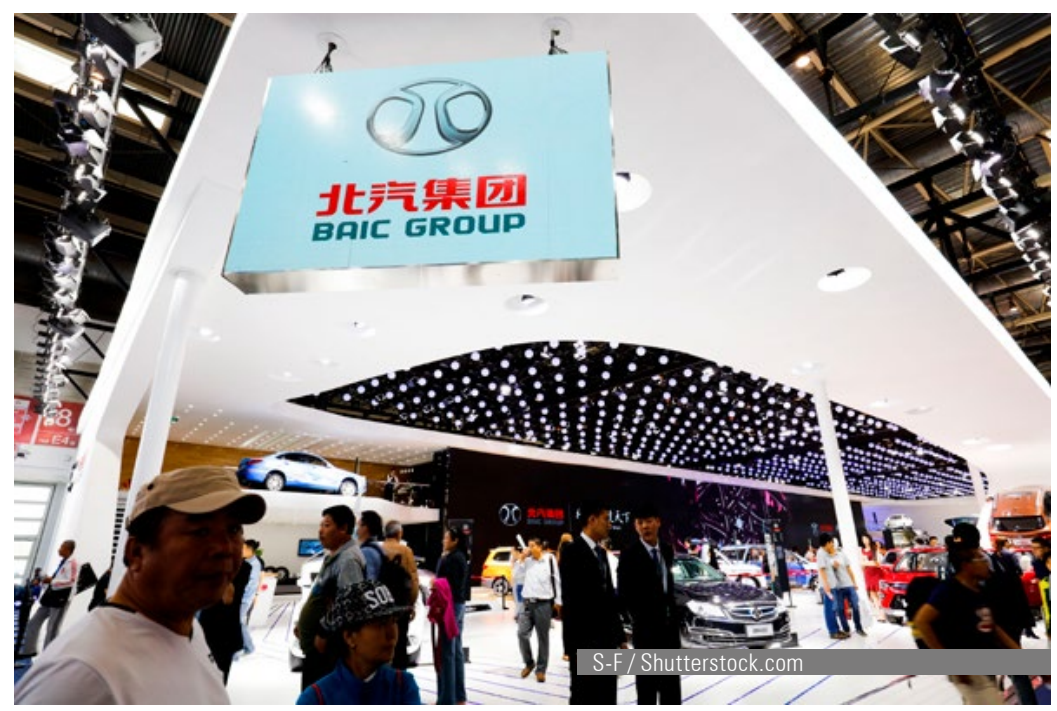

Inició sus operaciones en Chile en 2014 bajo la representación de Automotores Fortaleza, empresa distribuidora de vehículos chinos e indios que forma parte del grupo Gildemeister. Automotores Fortaleza es representante de una amplia gama de vehículos: automóviles, vehículos comerciales, ca- 
miones, buses y motos de las marcas Brilliance, Mahindra, BAIC, Geely, Yuejin, Sinotruck, Yutong, Benelli, Keeway y Linhai (Fortaleza, s.f.). Esta empresa distribuidora cuenta con una amplia red de 30 concesionarios a lo largo del país compuesto por puntos de venta, talleres de servicio técnico y locales de ventas de repuestos (BAIC Chile, s.f.). Para captar a los consumidores, BAIC planteó como estrategia ofrecer modelos competitivos y con la mejor garantía del mercado. BAIC brinda una garantía de siete años o 150 mil kilómetros, una oferta insuperable en el mercado chileno. Este tipo de estrategia permitió a BAIC crecer en 2017, registrando ventas de 1.555 SUV, mientras que para 2020 estas ventas decrecieron a 702 SUV (CAVEM, 2019) (ANAC, 2020).

En Colombia, la marca BAIC también ha estado presente desde 2014 bajo la representación de China Automotriz, empresa dedicada a la comercialización de vehículos utilitarios. Sin embargo, a partir de 2018 los vehículos de pasajeros de la marca BAIC comenzaron a ser comercializados por Praco Didacol S.A, empresa del grupo Inchcape. Con la introducción de la marca BAIC al mercado colombiano se inauguraron tres tiendas en la ciudad de Bogotá. Actualmente, cuenta con ocho establecimientos y talleres de repuestos a nivel nacional ubicados en las principales ciudades del país: Bogotá, Medellín, Cali, Bucaramanga, Pasto, y Pereira (PracoDidacol, 2017).

Estos vehículos destacan por su equipamiento y seguridad a un costo asequible. Praco Didacol ofrece una garantía de cinco años o 100.000 kilómetros para autos particulares, o de tres años o 60.000 kilómetros para servicio público (Restrepo, 2018).

A México, BAIC llegó en el segundo semestre de 2016 de la mano de Picacho Grupo Automotriz, distribuidora oficial de marcas como Ford, Mazda, Jaguar y Lincoln, entre otras, con más de 30 años de experiencia en el mercado. Se abrieron 10 concesionarios en Ciudad de México, Querétaro y Cuernavaca, para finales de ese mismo año se vendieron 670 unidades de los modelos DE 20 y X25. Esta cifra contrasta con las ventas que tuvieron Kia y Hyundai en su primer mes en el mercado mexicano - Kia vendió 1.499 unidades en julio de 2015, mientras que Hyundai vendió 705 unidades en mayo de 2014- (Rodríguez, 2017). En 2017, BAIC Motor comenzó a ensamblar vehículos en Veracruz, para ello se asoció con Automotive Trucks, fabricante de camiones Foton y vehículos de la marca DFSK, Lifan y Maxus en ese país. Para llevar a cabo la instalación de la línea de ensamblaje se demandó una inversión de 30 millones de dólares (Virgilio, 2017).

BAIC planea abastecer el mercado local en el corto plazo. A un mediano plazo, iniciará la exportación de sus vehículos a Sudamérica, Centroamérica y el Caribe y a largo plazo tiene planeado exportar a los mercados de Estados Unidos y Canadá. Para ello planea obtener el registro como armadora usando el $65 \%$ de los componentes locales, iniciar la construcción de una planta propia en el país y acogerse a las facilidades arancelarias de los Tratados de Libre Comercio (TLC) que México mantiene con otros países (Cantera S. , 2017) (CRI, 2017).

En Perú, BAIC está presente desde 2014 bajo la representación de Motormundo (El Comercio, 2015), empresa que forma parte del grupo Gildemeister representando marcas asiáticas como BAIC, Brilliance, Jinbei, Mahindra, JMC y Geely, cuenta con una amplia red de ventas, servicios y repuestos a lo largo de todo el territorio nacional (Motormundo, 2017). Esta empresa tiene una red de 23 concesionarios a nivel nacional, 5 ubicados en Lima y 18 en provincias. Asimismo, cuenta con cinco talleres que ofrecen servicio técnico (Motormundo, 2017). Algunos modelos que han tenido acogida en el mercado peruano son las SUV BAIC X25, X35, X55, entre otros. La cuota de participación de BAIC en el mercado peruano es muy baja en comparación al resto de marcas chinas analizadas (Changan, JAC y Great Wall) (AAP, 2021). 


\section{Conclusiones}

Finalmente, se presentan a continuación las principales conclusiones del presente capítulo:

La AP es la octava economía del mundo y produce cerca del $40 \%$ del PBI de ALC. En los últimos diez años se ha alcanzado un incremento promedio de $22 \%$ de la población económicamente activa, lo que representa una gran oportunidad para la industria automotriz china.

En Latinoamérica existen tres grupos de países, aquellos que ensamblan para su consumo local como Brasil; aquellos que importan vehículos y también ensamblan para abastecer el mercado interno y externo, como Colombia, Ecuador y México; y aquellos que solo importan para su consumo local, debido a que no tienen industria automotriz, como son los casos de Chile y Perú.

En el último año, México produjo 3'040.178 vehículos ligeros, de los cuales el 68,2 \% corresponden a vehículos comerciales ligeros, mientras que el resto corresponde a la fabricación de automóviles. Asimismo, durante ese año se exportaron 2'681.806 unidades. A pesar de que empresas como JAC y BAIC se han instalado recientemente en ese país, se espera que en los próximos años los vehículos producidos en México se distribuyan hacia otros países de la región.

En cuanto a la distribución de los vehículos, las empresas del sector automotor están optando por la omnicanalidad que, entre otras ventajas competitivas, permite la personalización y mejor entrega de los automóviles vendidos. Además de un mejor servicio posventa.

Como parte de las oportunidades de crecimiento, estos países miembros de la Alianza del Pacífico están apostando por mejorar la eficiencia de sus respectivos parques vehiculares, así como reducir los costos asociados por contaminación del aire que pueden afectar la salud pública. Entre estas iniciativas, Chile y Colombia han suscrito convenios para que empresas chinas como BYD les puedan suministrar flotas de autobuses eléctricos, renovando así su parque automotor. Mientras que, en Perú, las iniciativas por incentivar la electromovilidad en el sistema de transporte público están en período de prueba.

Con respecto a las marcas chinas, estas se encuentran competiendo en los diferentes segmentos del mercado. Su bajo precio permitió que algunas de estas ingresaran a competir en segmentos de vehículos comerciales o de carga; y una vez que alcanzaron cierto nivel de aceptación ampliaron su catálogo de productos, incursionando así en otros segmentos como el de vehículos ligeros.

En los últimos años, las marcas chinas han apostado por mejorar sus productos con la finalidad de ganar mayor aceptación en el mercado. Para ello, han invertido en áreas de investigación y desarrollo, han suscrito convenios con concesionarios locales para la distribución y comercialización de vehículos en los diferentes países y, en algunos casos, han optado por instalar plantas de ensamblaje con la finalidad de poder entrar a un mercado y expandirse posteriormente a la región.

La instalación de estas plantas ensambladoras ha dado origen al desarrollo de cadenas productivas para el suministro de parte e insumos para el ensamblaje y mantenimiento de vehículos, como es el caso de Chile y Perú, países que cuentan con reservas de litio.

Finalmente, señalar que la participación de mercado de las marcas chinas en los países de la AP ha ido creciendo a pasos agigantados, se observa que desde el ingreso de las marcas a estos mercados su comercialización se ha más que triplicado. 


\section{Referencias}

- $\quad$ AAP. (1 de marzo de 2019). Los efectos de un parque automotor escaso y antiguo. Recuperado el 12 de enero de 2021, de AAP: https://aap.org.pe/aap-los-efectos-de-un-parque-automotor-escaso-y-antiguo-2/

- $\quad$ AAP. (10 de noviembre de 2020). Fomento de chatarreo debe acelerarse. Recuperado el 12 de enero de 2021, de Asociación automotriz del Perú (AAP): https://aap.org.pe/asociacion-automotriz-del-perufomento-de-chatarreo-debo-acelerarse/

- $\quad$ AAP. (enero de 2021). Informe del sector automotor a diciembre 2020. Recuperado el 12 de enero de 2021, de Asociación Automotriz del Perú (AAP): https://aap.org.pe/informes-estadisticos/diciembre-2020/

- $\quad$ ACARA. (31 de agosto de 2020). Mercado automotor latinoamericano. Recuperado el 7 de enero de 2021, de ACARA: https://www.acara.org.ar/files/downloads/PPT \%20de \%20Congreso \%20de \%20Negocios \%20de \%20la \%20Industria \%20Automotriz \%20Latinoamericana \%203.pdf

- Al Volante. (2008). China Changan montará planta en México; Ford dice no ir. Recuperado el 17 de marzo de 2018, de Al Volante: http://www.alvolante.info/nacionales/china-changan-montara-planta-en-mexicoford-dice-no-ir/

- Ambacar. (2018). Historia. Recuperado 28 de enero de 2019, de Ambacar: http://www.ambacar.com/ historia.html

- América Economía. (19 de octubre de 2017). Marcas chinas se consolidan en Chile. Recuperado el 11 de febrero de 2019, de Asia Link: https://asialink.americaeconomia.com/economia-y-negocios-automotriz/ marcas-chinas-se-consolidan-en-chile

- $\quad$ ANAC. (2008). Informe de Mercado automotor Ene-Dic. 2008. Recuperado el 13 de enero de 2021, de Asociación Nacional Automotriz de Chile (ANAC): https://www.anac.cl/wp-content/uploads/2018/12/ cifras_liv_med_camiones_enero_diciembre_2008.pdf

- $\quad$ ANAC. (diciembre de 2020). Informe del mercado automotor. Recuperado el 6 de enero de 2021, de ANAC: https://www.anac.cl/wp-content/uploads/2021/01/12-ANAC-Mercado-Automotor-Diciembre-2020.pdf

- ANAC. (enero de 2021). Conferencia de prensa ANAC 2021. Recuperado el 6 de enero de 2021, de ANAC: https://www.anac.cl/wp-content/uploads/2021/01/CONFERENCIA-DE-PRENSA-ANAC-2021.pdf

- Andemos. (2018). Informe vehículos Diciembre Colombia, 2018. Recuperado el 16 de febrero de 2019, de Asociación Colombiana de Vehículos Automotores - Andemos: http://www.andemos.org/wp-content/ uploads/2019/01/Informe-Vehiculos-2018-12.pdf

- Andemos. (Diciembre de 2019). Informe vehículos Diciembre Colombia, 2019. Recuperado el 14 de enero de 2021, de http://www.andemos.org/wp-content/uploads/2020/01/Informe-Vehiculos-2019-12.pdf

- Andemos. (diciembre de 2020). Cifras y estadísticas. Recuperado el 8 de enero de 2021, de Andemos: https://www.andemos.org/index.php/cifras-y-estadisticas-version-2/

- Andemos. (4 de enero de 2021). Diciembre 2020: El mercado colombiano cerró con 188.655 unidades en 2020. Recuperado el 8 de enero de 2021, de Andemos: https://www.andemos.org/index.php/2021/01/04/ el-mercado-colombiano-cerro-con-188-655-unidades-en-el-2020/

- Autosdeprimera.com. (14 de abril de 2011). La camioneta china Great Wall Haval 3 llega a Colombia para competir en el segmento de las SUV desde $\$ 45^{\prime} 900.000$. Obtenido de Autosdeprimera.com: https://autosdeprimera.com/Lanzamientos/la-camioneta-china-great-wall-haval-3-Ilega-a-colombia-paracompetir-en-el-segmento-de-las-suv-desde-45a900000

- BAIC Chile. (s.f.). Red de atención BAIC. Recuperado el 14 de febrero de 2019, de BAIC Chile: https://www. baic.cl/red-de-atencion

- BAIC Perú. (2021). ¿Quién es BAIC. Recuperado el 13 de enero de 2021, de BAIC Perú: https://baic.pe/ por-que-baic/

- BBVA Research. (Diciembre de 2010). Situación Automotriz. Recuperado 20 de enero de 2021, de BBVA Research: https://www.bbvaresearch.com/wp-content/uploads/mult/ESTAULT_14122010_tcm346239499.pdf

- $\quad$ BBVA Research. (14 de marzo de 2018). Situación Automotriz Colombia 2018. Recuperado el 14 de diciembre de 2018, de BBVA Research: https://www.bbvaresearch.com/wp-content/uploads/2018/03/ SituacionAutomotriz2018.pdf

- $\quad$ BBVA Research. (20 de febrero de 2020). México - Sector automotriz: retos y oportunidades. Recuperado el 11 de enero de 2021, de BBVA Research: https://www.bbvaresearch.com/publicaciones/mexico-sectorautomotriz-retos-y-oportunidades/

- Bermúdez, A. (13 de noviembre de 2011). Los fabricantes chinos de autos se expanden en América latina. Recuperado el 08 de agosto de 2018, de La Nación: https://www.lanacion.com.ar/1422569-losfabricantes-chinos-de-autos-se-expanden-en-america-latinaexpansion

- Bloomberg. (2021). Anhui Jianghuai Automobile Group Co Ltd/Dup. Recuperado el 13 de enero de 2021, de Bloomberg: https://www.bloomberg.com/profile/company/AJAGZ:CH

- Bloomberg. (2021). BAIC Motor Corp Ltd. Recuperado el 13 de enero de 2021, de Bloomberg: https:// www.bloomberg.com/profile/company/1958:HK 
- Bloomberg. (2021). Changan Automobile Co Ltd. Recuperado el 13 de enero de 2021, de Bloomberg: https://www.bloomberg.com/profile/company/0625615D:CH

- Bloomberg. (2021). Great Wall Motor Co Ltd. Recuperado el 13 de enero de 2021, de Bloomberg: https:// www.bloomberg.com/profile/company/2333:HK

- Cantera, S. (24 de mayo de 2017). BAIC abre en Veracruz línea de ensamble. Recuperado el 13 de diciembre de 2018, de El Universal: https://www.eluniversal.com.mx/articulo/cartera/negocios/2017/05/24/baicabre-en-veracruz-linea-de-ensamble

- Cantera, S. (15 de marzo de 2018). JAC vende 1 mil 200 vehículos en México en 2017. Recuperado el 06 de diciembre de 2018, de El Universal: http://www.eluniversal.com.mx/cartera/economia/jac-vende-1-mil200-vehiculos-en-mexico-en-2017

- CAVEM. (05 de febrero de 2019). Mercado Automotor Global 2018. Recuperado el 12 de febrero de 2019, de Cámara Nacional de Comercio Automotriz de Chile - CAVEM: https://www.cavem.cl/ informes/5c3f3da9ef6ad.pdf

- CAVEM. (Setiembre de 2020). Anuario Estadístico Automotor 2019. Recuperado el 06 de enero de 2021, de Cámara Nacional de Comercio Automotriz de Chile (CAVEM): https://www.cavem.cl/ informes/5f5a4a6f0c47f.pdf

- Changan Colombia. (2021). Changan Auto. Recuperado el 14 de enero de 2021, de Changan Colombia: https://changan.com.co/\#

- CRI. (24 de mayo de 2017). Automotriz china BAIC comienza ensamblado de subcompacto en planta del este de México. Recuperado el 13 de diciembre de 2018, de China Radio International: http://espanol.cri. cn/2786/2017/05/24/289s410836.htm

- Datosmacro.com. (enero de 2021). Colombia: Economía y demografía. Recuperado el 07 de enero de 2021, de datosmacro.com: https://datosmacro.expansion.com/paises/colombia\#: : :text=Colombia \%2C \%20 con \%20una \%20poblaci \%C3 \%B3n \%20de,y \%20su \%20moneda \%20Pesos \%20colombianos.

- Derco Perú. (s.f.). Modelos. Recuperado el 06 de febrero de 2019, de Great Wall: https://www.greatwall. com.pe/

- Derco Perú. (s.f.). Puntos de venta. Recuperado el 08 de febrero de 2019, de Mundo JAC: https:// mundojac.com/

- Diario Expreso. (12 de marzo de 2018). La ensambladora local Ciauto inyecta capital con mira a exportar. Recuperado 28 de enero de 2019, de Pressreader: https://www.pressreader.com/

- El Comercio. (12 de febrero de 2015). Motormundo espera vender 2.400 autos en 2015. Recuperado el 11 de febrero de 2019, de El Comercio: https://elcomercio.pe/ruedas-tuercas/automotriz/motormundoespera-vender-2-400-autos-2015-333457

- El Comercio. (23 de febrero de 2018). Conoce cómo le va al mercado automotor en el Perú. Recuperado el 31 de enero de 2019, de El Comercio: https://elcomercio.pe/suplementos/comercial/mercado-vehicular/ conoce-como-le-va-al-mercado-automotor-peru-1003297

- El Espectador. (18 de noviembre de 2016). Marcas chinas le apuestan a la calidad en el Salón del Automóvil. Recuperado 29 de enero de 2019, de El espectador: https://www.elespectador.com/vivir/autos/marcaschinas-le-apuestan-calidad-el-salon-del-automovi-articulo-665157

- El Tiempo. (18 de agosto de 2015). La marca china Foton inagura hoy su planta de ensamblaje en Colombia. Recuperado el 8 de enero de 2021, de El tiempo: https://www.motor.com.co/actualidad/industria/fotoninaugura-planta-ensamblaje-colombia/23261

- El Tiempo. (25 de enero de 2020). Colombia en cifras según el Registro Único Nacional de Tránsito. Recuperado el 7 de enero de 2021, de El Tiempo: https://www.eltiempo.com/economia/sectores/ colombia-en-cifras-segun-el-registro-unico-nacional-de-transito-455152\#: - :text=Veamos \%3A \%20El \%20Runt \%20reporta \%20la,de \%20revisi \%C3 \%B3n \%20t \%C3 \%A9cnico \%20mec \%C3 \%A1nica \%20 vigentes.

- Enriquez, C. (09 de marzo de 2018). Ciauto planea exportar a Colombia. Recuperado 28 de enero de 2019, de Revista Líderes: https://www.revistalideres.ec/lideres/ciauto-exportar-colombia-vehiculos-comercio. html

- Europa Press. (11 de febrero de 2009). El grupo chino Changan se alía con la hispanoamericana Autopark para fabricar coches en México. Recuperado el 08 de agosto de 2018, de Europa Press: http://www. europapress.es/economia/noticia-economia-motor-grupo-chino-changan-alia-hispanoamericanaautopark-fabricar-coches-mexico-20090211112322.html

- EY. (2018). Guía de Negocios e Inversión de la Alianza del Pacífico 2018-2019. Recuperado el 10 de enero de 2021, de Ministerio de Relaciones Exteriores: https://cdn.www.gob.pe/uploads/document/ file/205437/Guia_de_la_Alianza_de_Pacifico_2018-2019.pdf

- Farias, R. (12 de setiembre de 2017). JAC lanza ediciones especiales "Full Conectadas a Internet". Recuperado el 14 de febrero de 2019, de RutaMotor: https://www.rutamotor.com/solo-2-meses-jac-ponedisposicion-clientes-ediciones-especiales-full-conectadas-internet/ 
- Fitzen, L. (2007). Multi Channel Retailling in the Automative Industry. Edinburgh: Napier University of Edinburgh.

- Fortaleza. (s.f.). Home. Recuperado el 14 de febrero de 2019, de Fortaleza: http://www.fortaleza.cl/

- Gachúz, J. C. (2011). La crisis mundial en el sector automotriz, China: ¿aliadoestratégico de México? Análisis Económico, XXVI(63). Obtenido de https://www.redalyc.org/pdf/413/41322447006.pdf

- González, E. (2015). Distribución exclusiva y competencia. Trimestre económico, 403 - 432.

- González, L. (01 de febrero de 2017). Forman alianza para fabricar autos chinos en México. Recuperado el 05 de diciembre de 2018, de El Economista: https://www.eleconomista.com.mx/empresas/Formanalianza-para-fabricar-autos-chinos-en-Mexico-20170202-0151.html

- Gutiérrez, J. (06 de febrero de 2019). Great Wall alcanza las 60 mil unidades comercializadas en Chile. Recuperado el 13 de febrero de 2019, de La Tercera: https://www.latercera.com/mtonline/noticia/greatwall-chile/518495/

- Homburg, C., Schäfer, H., \& Schneider, J. (2012). Sales Excellence Systematic Sales Management. Berlín. doi:10.1007/978-3-642-29169-2

- INEGI. (2019). Total nacional de vehículos. Recuperado el 14 de febrero de 2019, de Instituto Nacional de Estadística y Geografía - INEGI: http://www.beta.inegi.org.mx/temas/vehiculos/

- INEGI. (8 de enero de 2021). Resultados del registro administrativo de la industria automotriz de vehículos ligeros correspondiente a diciembre de 2020. Recuperado el 14 de enero de 2021, de INEGl: https://www. inegi.org.mx/contenidos/saladeprensa/boletines/2021/rm_raiavl/rm_raiavl2021_01.pdf

- Jian, Y. (22 de julio de 2009). Changan intends to hire Magna to assemble cars in Mexico. Recuperado el 18 de agosto de 2018, de Automotive News China: http://www.autonewschina.com/en/article.asp?id=2909

- Kamiya, M., \& Ramirez, C. (2004). La industria automotriz: Desarrollos en China y sus implicancias para Latinoamérica. Cuadernos de difusión, 6-18.

- La Tercera. (14 de enero de 2020). Marcas chinas de autos superaron a las de EEUU en 2019 y quedaron terceras en Chile. Recuperado el 07 de enero de 2021, de La Tercera: https://www.latercera.com/pulso/ noticia/marcas-chinas-autos-superaron-las-ee-uu-2019-quedaron-terceras-chile/972660/

- Marklines. (s.f.). Marklines. Obtenido de https://www.marklines.com/en/vehicle_sales/search

- Motormundo. (2017). Página principal. Recuperado el 11 de febrero de 2019, de Motormundo: http:// www.motormundo.pe/

- Portafolio. (19 de abril de 2017). La china JMC proyecta hacer planta de ensamblaje en el país. Recuperado el 8 de enero de 2021, de Portafolio: https://www.portafolio.co/negocios/empresas/jmc-proyecta-hacerplanta-de-ensamblaje-en-el-pais-505072

- Posada, C. (2018). Aumento continuo del parque automotor, un problema que urge solucionar. (C. d. Lima, Ed.) Obtenido de Cámara de Comercio de Lima: https://www.camaralima.org.pe/repositorioaps/0/0/par/ r816 3/comercio \%20exterior.pdf

- PracoDidacol. (2017). Nuestras sedes - BAIC. Recuperado el 31 de enero de 2019, de PracoDidacol: https://site.pracodidacol.com/sedes-baic-en-concesionario-autorizado-en-bogota-colombia-praco-didacol

- Restrepo, 0. (09 de febrero de 2018). BAIC X25 y X35: Características, equipamiento y precios en Colombia. Recuperado el 31 de enero de 2019, de El carro colombiano: https://www.elcarrocolombiano. com/lanzamientos/baic-x25-y-x35-caracteristicas-equipamiento-y-precios-en-colombia/

- Reuters. (05 de abril de 2017). Great Wall Motor evalúa construir planta en México. Recuperado el 11 de diciembre de 2018, de El Economista: https://www.eleconomista.com.mx/empresas/Great-Wall-Motorevalua-construir-planta-en-Mexico-20170406-0066.html

- Reuters. (12 de diciembre de 2018). Chile enciende la chispa del transporte público eléctrico en América Latina. Recuperado el 12 de febrero de 2019, de Gestión: https://gestion.pe/mundo/internacional/chileenciende-chispa-transporte-publico-electrico-america-latina-252536?fbclid=IwAR3XKVkpbK4wREgKDeN HK__3gg8YmkAXcQNeepTcdVosRDOApc_G1imG444

- Revista Carga Pesada. (01 de abril de 2014). China Automotriz celebra diez años en Colombia. Recuperado 28 de enero de 2019, de Revista Carga Pesada: http://revistacargapesada.com/china-automotriz-celebradiez-anos-en-colombia/

- Rodríguez, I. (24 de Mayo de 2017). ¿Qué tanto éxito tienen los autos chinos en México? Recuperado 20 de enero de 2021, de Expansión: https://expansion.mx/empresas/2017/05/24/que-tanto-exito-han-tenidolos-autos-chinos-en-mexico

- RUNT. (2018). Estadísticas del RUNT. Recuperado el 15 de enero de 2019, de RUNT: https://www.runt.com. co/cifras?field_fecha_de_la_norma_value $\% 5$ Bvalue $\% 5 \mathrm{D} \% 5$ Byear $\% 5 \mathrm{D}=2018 \mathrm{gfield}$ grafica_value $=5$

- Sánchez, A. (14 de julio de 2017). La mitad de los autos que se venden en México son asiáticos. Recuperado el 11 de diciembre de 2018, de El Financiero: http://www.elfinanciero.com.mx/empresas/50de-los-autos-que-se-venden-en-mexico-ya-son-asiaticos

- Vanguardia. (09 de marzo de 2017). Automotriz china se arrepiente y no instalará planta en México por amenazas de Trump. Recuperado el 4 de diciembre de 2018, de Vanguardia: https://vanguardia.com.mx/ articulo/automotriz-china-se-arrepiente-y-no-instalara-planta-en-mexico-por-amenazas-de-trump 
- Virgilio, J. (24 de mayo de 2017). BAIC México inaugura línea de ensamble en Veracruz. Recuperado el 13 de diciembre de 2018, de Automóvil Panamericano: http://www.automovilonline.com.mx/article/baicmexico-inaugura-linea-de-ensamble-en-veracruz 